\title{
Shifts in foraging behavior of wintering Hooded Cranes (Grus monacha) in three different habitats at Shengjin Lake, China
}

Wenjing Wan 1,2,3, Lizhi Zhou ${ }^{1,2,3^{*}}$ and Yunwei Song 1,2,3,4

\begin{abstract}
Background: Wetland loss and degradation result in a reduction in the availability and quality of food for wintering waterbirds. Birds normally modify their foraging behavior to adapt to variations in food availability. In this study, we compared shifts in foraging behavior of Hooded Cranes (Grus monacha) in three different habitats at Shengjin Lake, China to understand the response of these cranes to changes in habitat.

Methods: We investigated the food density and foraging behavior of Hooded Cranes in Shengjin Lake National Nature Reserve from November 2014 to April 2015. We used regression equations to describe the changes in food density. A total of 397 behavioral observations were used in the analyses of their foraging efforts. We fitted a candidate set of generalized mixed linear models to analyze the relationship of foraging efforts and food density. We used a method of information theory to guide the selection of the model and Akaike's Information Criterion to calculate the value of each model. The relationship between food density, disturbances and foraging behavior was illustrated using a generalized linear model.
\end{abstract}

Results: Along with the temporal variation and exploitation of food biomass, the food density varied widely among foraging sites. During the early winter period, foraging efforts were more pronounced in the paddy fields and meadows but not significantly different among the three habitats. The cranes spent more foraging effort in the paddy fields and meadows during the middle stage and in the meadows and mudflats during the late winter. The results of the generalized linear model showed that food density and disturbances had different effects on the rate of foraging success during the winter, while the effect of foraging effort was not significant. Furthermore, the rate of feeding success was markedly affected by disturbances in the paddy fields. The combined action of food density and disturbances had a significant effect on the rate of foraging success in the meadows, while the effect of foraging effort was also not significant in three habitats.

Conclusions: Changes in foraging behavior were significant in three habitats, which were affected by food density and disturbances. The rate of foraging success increased in the habitat with low food density and low disturbances to increase the foraging efficiency in the lake. With abundant food and a high level of disturbance, the rate of foraging success decreased to ensure more secure access to food.

Keywords: Food density, Foraging behavior, Habitat quality, Hooded Crane

\section{Background}

Food abundance and availability affect modes of foraging behavior on the part of animals (Pyke et al. 1977). When

\footnotetext{
*Correspondence: zhoulz@ahu.edu.cn

1 School of Resources and Environmental Engineering, Anhui University, 111 Jiulong Road, Hefei 230601, China

Full list of author information is available at the end of the article
}

faced with variation in the availability of food resources, animals tend to adjust their foraging behavior (Stephens and Krebs 1986). According to the optimal foraging theory, animals select foraging patches that allow them to reduce their cost and maximize the efficiency of energy intake (Krebs 1978; Krebs et al. 1983; Pyke 1984; May and Mclean 2010). It follows then that animals typically select 
food sources and employ foraging behavior that optimize energy intake (Stephens and Krebs 1986). Waterbirds assemble in areas with abundant food sources to meet their energy requirements for overwintering and as well, they adjust their behavior to maximize feeding efficiency (Beauchamp 2003).

In fact, when accessible, some waterbirds are specialists in consuming Vallisneria tubers, which is high in energy, highly digestible and readily found in shallow water or soft mud (Fox et al. 2011). With wetland degradation and the loss of suitable habitats, the number and species of large submerged vascular plants are reduced and birds adjust their behavior to adapt to this change. Reductions in food availability force animals to move to habitats with higher food densities, such as paddy fields (Zheng et al. 2015). Changes in food availability directly affect the foraging effort of waterbirds (Tome 1988). In areas with high food availability, foraging effort is reduced because of the likelihood of finding food easily (Yasué 2006). Many species adjust their foraging efforts, or alter their foraging time, in response to changes in food resource availability (Hill and Ellis 1984). Under the conditions of wetland degradation and habitat loss, waterbirds are forced to feed in areas severely disturbed by humans. As well, they need to increase their vigilance and reduce foraging time to ensure more secure access to food (Li et al. 2015).

Hooded Cranes are largely reliant upon feeding in wetlands for food supplies such as the tubers of the submerged macrophytes Potamogeton pectinatus, Vallisneria spiralis and Vallisneria spinulosa, which were formerly widespread and abundant during the 1970s and 1980s (Meng 1979). However, human activities have destroyed the balance of the wetland ecosystem of lakes, largely reducing the abundance of these submerged macrophytes. Traditional food sources cannot meet the consumption demand for energy and nutrition of the cranes (Barzen et al. 2009). Hence, Potentilla supine, Ranunculus polii and Polygonum criopolitanum have become important overwintering sources of food in order for these cranes to survive. This food scarcity also forces the Hooded Cranes to utilize farmland to supplement their foraging (Zhang and Lu 1999; Fox et al. 2008). The collapse of submerged plants in lakes, the shrinking number of tubers of Vallisneria spiralis and their fragmented distribution have a detrimental effect on the distribution and foraging behavior of Hooded Cranes (Fox et al. 2011). As the capacity of their natural habitat decreases, the cranes have shown flexible foraging strategies, by transferring to fallow paddy fields to forage and to supplement their food sources (Zheng et al. 2015).

We observed the foraging behavior of Hooded Cranes wintering at Shengjin Lake, China, to study the effects of food density and availability on their behavior. We compared shifts in their foraging behavior in three different habitats to understand the response of the cranes to changes in habitat. Our results would provide references to understanding the foraging strategy of these birds under environmental pressure and suggest targeted conservation strategies for the Hooded Crane.

\section{Methods \\ Study area}

Shengjin Lake $\left(30^{\circ} 15^{\prime}-30^{\circ} 30^{\prime} \mathrm{N}, 116^{\circ} 55^{\prime}-117^{\circ} 15^{\prime} \mathrm{E}\right)$ is located in the middle and lower Yangtze River floodplain, one of the main wintering grounds for Hooded Cranes in China (Fang et al. 2006; Cao et al. 2008). Our study site is located in the upper part of Shengjin Lake where most of the cranes gather and abundant aquatic food sources for the cranes are found (Cheng et al. 2009). At Shengjin Lake the traditional foods of the Hooded Crane are submerged macrophyte tubers (Barzen et al. 2009), but more recently the cranes have also been feeding on Potentilla supine, Ranunculus polii and the like. During the autumn and winter drawdown, mudflats are exposed and the waterbirds feed on Anodonta woodiana (Zhang and Lu 1999; Fox et al. 2008). As a consequence of wetland degradation and habitat loss, the carrying capacity of these wetlands has decreased and the traditional food sources of these wintering waterbirds have experienced a sharp decline in quantity (Li et al. 2015). The cranes have shifted habitat from mudflats to farmland, such as harvested paddy fields with rice grains, to look for supplementary sources of food (Yang et al. 2015).

\section{Habitat survey}

We selected six sampling sites covering the three habitats in the main foraging areas of the Hooded Crane in the winter of 2014/2015 (Fig. 1). Each sampling site measuring $150 \mathrm{~m} \times 150 \mathrm{~m}$, was chosen to estimate food density for the specific date of each observation of foraging effort and foraging success. We estimated daily food-density values for each plot from regression equations. Our cranes mainly exploit Anodonta woodiana, mollus and small amounts of tubers of wetland vegetation from the bare substrate of the lake bottom in the mudflats. Potentilla supina, Ranunculus polii and Polygonum criopolitanum with high digestibility were obtained from meadows and rice grains (Olyza sativa) from paddy fields (Zheng et al. 2015). To investigate food density, we sampled the plots three times, i.e., at the arrival of the cranes at the lake (during the fall from 23 September to 17 October 2014), in the middle of the winter (from 5 to 25 January 2015) and at the departure of the cranes from Shengjin Lake (in the spring from 1 to 12 April 2015). Quadrats measuring $0.50 \mathrm{~m} \times 0.50 \mathrm{~m}$ were excavated to a depth of $0.30 \mathrm{~m}$, below which tubers were considered inaccessible 


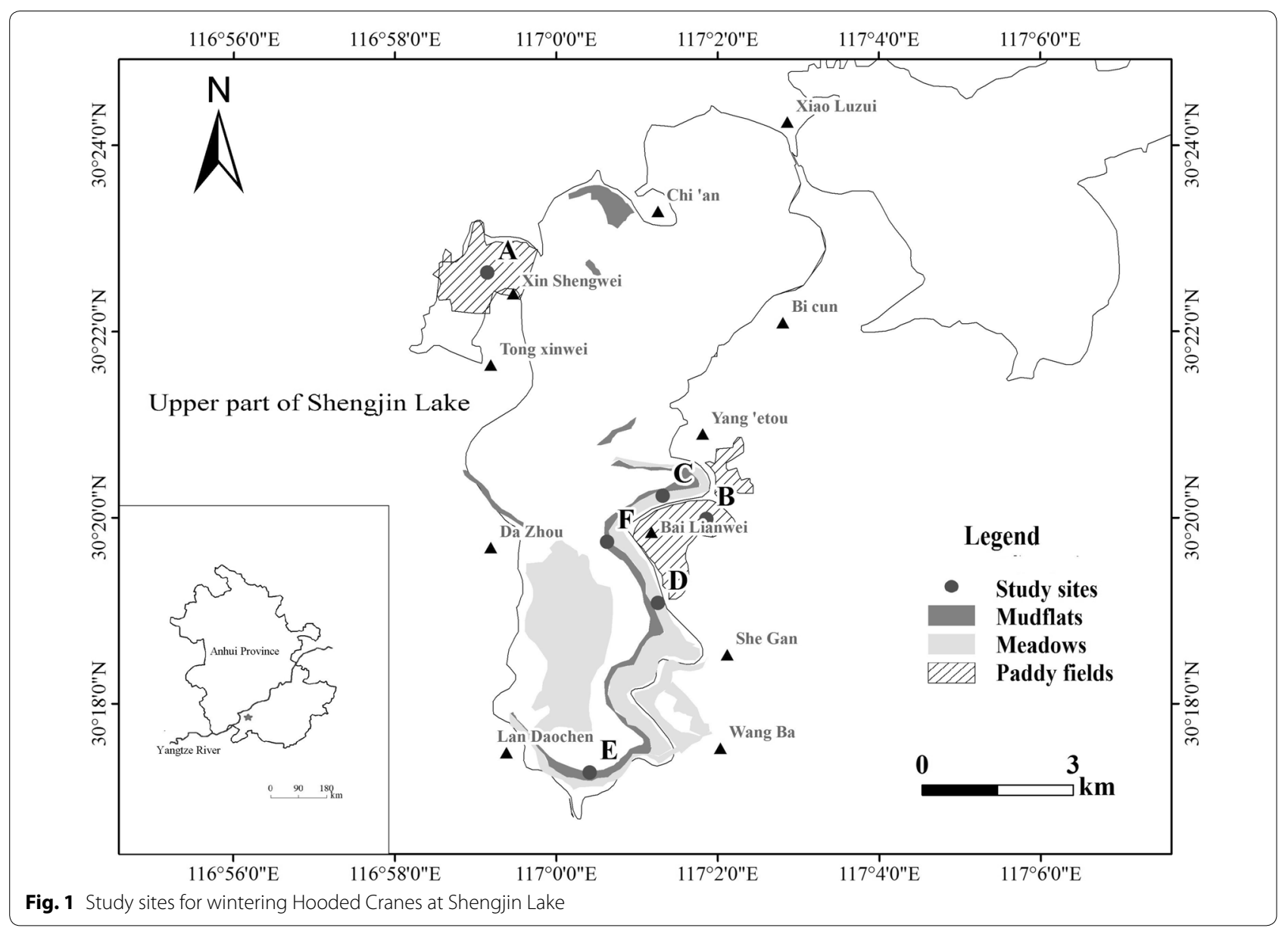

to foraging cranes (Lovvorn 1989; Richman and Lovvorn 2003). During the three over-wintering periods, a total of 381 samples from these quadrats were collected, of which 43, 62 and 30 in meadows, 25, 29 and 55 in paddy fields and 47, 60 and 30 in the mudflats from the early, middle to late wintering stages, respectively (Gillespie and Kronlund 1999). The locations of the fall quadrats were not resampled in the spring (Lewis et al. 2007).

\section{Behavior sampling}

We collected behavioral data from November 2014 to April 2015. Hooded Cranes were located during regular-route surveys and locations were recorded with a GPS. Routes were never repeated on the same day to avoid pseudo replication. Focal samplings were carried out using binoculars $(8 \times)$ or a telescope $(20-60 \times)$. We defined November and December as the early wintering period; January and February of the following year as the mid-wintering period and March and early April as the late wintering period (Zheng et al. 2015). At the start of each focal observation, the location, date, time of day (morning, noon, afternoon), habitat type (meadows, mudflats, paddy fields), winter stage (early winter, midwinter, or late winter), age (adult or juvenile) and family size (including 0,1 or 2 juveniles) were recorded. A digital voice recorder was used to record behavioral events for 20 min unless we lost sight of the individual focal bird. We concentrated on studying the foraging behavior of Hooded Cranes, specifically their behavior in searching for food, handling food and swallowing.

\section{Statistical analyses}

In total, 397 behavioral observations were used in the analyses of foraging efforts. Foraging effort is defined as the ratio of total amount of time spent searching for and processing food and the activity time budget. If the head and neck of a crane lift backwards twice in a quick highfrequency tic when foraging and they then swallow, this means they have had foraging success. The rate of foraging success is defined as the ratio of the amount of food captured and the time required for foraging. We fitted a set of candidate generalized mixed linear models (Littell 
et al. 2000) in SPSS 19. We used a quadratic relationship $\left(\right.$ date + date $\left.^{2}\right)$ for the date (Date), where Date was scaled so that 1 November $2014=1$ to account for well-established patterns in foraging efforts that vary nonlinearly over the winter (Guillemette 1998; Fischer and Griffin 2000; Systad et al. 2000). Age and family size were considered in combination and referred to as "individual effects" (Individual) (Li et al. 2013). Time of day, habitat and winter period were referred to together as "Environmental effects" (Environmental). Date, individual, environmental and food density (Density) were used as units for the construction of the model.

Candidate models were made up of all single-variable models and additive models. The null model contained only the intercept and had no interactions, because there is no strong ecological explanation. For all models, the number of parameters $(k)$ included intercept and variance estimates. Covariance structures for repeated measures included one parameter $(k)$ for all models except for the null model. The foraging success rate may have included repeated observations of an individual crane. We allowed individual cranes to be random factors in order to control for repeated measurements. In the final model, we only included the habitat types (meadow, mudflat, paddy field), age (adult, juvenile), family size (2, 3 or 4 members), time of the day (morning, noon, afternoon), winter stage (early winter, mid-winter, or late winter), date and density. We used the method of information theory to guide the selection of the model and Akaike's Information Criterion (AIC) to calculate the value of each model. We used the relative importance of each AIC and their weight, $w_{i}(i=1, \ldots 16)$ for drawing inferences from each model. To calculate the relative importance of each explanatory variable in a candidate model, we added the weights of all explanatory variables contained in each candidate model (Kuwae et al. 2010).

We studied the responses of foraging behavior to changes of food density and disturbances by analyzing their rate of feeding success and feeding effort. According to the frequency and distance of disturbances observed during the survey, we divided the intensity of disturbances into three grades (Jiang et al. 2007; Yang et al. 2015). The data of density, disturbances, feeding success and foraging effort were tested for normality by using the one-sample Kolmogorov-Smirnov test. If the data followed a normal distribution we used a one-way ANOVA or a $t$ test for our analyses; if the data did not follow a normal distribution we used the non-parametric Kruskal-Wallis $H$ and the Mann-Whitney $U$ tests. As well, the effects of food density and disturbances on the foraging behavior were analyzed in a generalized linear model.

\section{Results}

\section{Food density and foraging activities}

During the early winter, the food density was high in the meadows $\left(212.200 \pm 141.144 \mathrm{~g} / \mathrm{m}^{2}, n=43\right)$, lower in the paddy fields $\left(123.395 \pm 25.699 \mathrm{~g} / \mathrm{m}^{2}, n=25\right)$ and lowest in the mudflats $\left(14.023 \pm 5.897 \mathrm{~g} / \mathrm{m}^{2}, n=47\right)$. During the middle stage, the food density in the paddy fields decreased significantly $\left(93.206 \pm 28.547 \mathrm{~g} / \mathrm{m}^{2}\right.$, $n=29$ ), while there was almost no change in the meadows and mudflats. During the late winter, the food density decreased significantly in all three habitats (Table 1). Along with the temporal variation and the exploitation of food biomass, food density varied widely among the three study sites.

The rate of foraging success of the cranes was high in the paddy fields $(0.105 \pm 0.051$ times/s in early winter and $0.099 \pm 0.057$ times/s in mid-winter) and low in the mudflats $(0.048 \pm 0.048$ times/s in early winter and $0.031 \pm 0.024 \mathrm{times} / \mathrm{s}$ in mid-winter). In the late winter, the rate of foraging success was high in the meadows $(0.070 \pm 0.038$ times/s, $n=30)$ and low in the mudflats $(0.048 \pm 0.022$ times/s, $n=30)$ (Table 1$)$. In the meadow and mudflat habitats, the rate of foraging success decreased with increases in food density and increased with decreases in food density during the winter periods. In early winter, foraging efforts were not significantly different among the three habitats. The cranes spent more foraging effort in the paddy field $(0.752 \pm 0.202, n=58)$ and meadows $(0.781 \pm 0.165, n=66)$ in the middle winter and in the meadows $(0.773 \pm 0.156, n=41)$ and mudflats $(0.740 \pm 0.102, n=14)$ in the late winter (Table 1$)$.

\section{Food density estimates for specific dates}

Food density in the mudflat habitat ranged between 12.8 and $17.2 \mathrm{~g} / \mathrm{m}^{2}$ and in the meadow and in the paddy habitats between 119.2 and $209.7 \mathrm{~g} / \mathrm{m}^{2}$ (Table 2). In the 2014/2015 winter, the total variation in food density ranged between 0.376 and $9.914 \mathrm{~g} / \mathrm{m}^{2}$ in the mudflats and from 68.8 to $256.3 \mathrm{~g} / \mathrm{m}^{2}$ at the other sampling sites. The average standard error of the mean value of the food density was only $15 \%$ in the mudflats and meadows. These low standard errors suggest our sampling procedure provided a good picture of the distribution of food sources.

\section{Model construction to quantify foraging effort}

The most suitable model to explain the changes in the feeding efforts of the cranes includes the date as a separate explanatory variable (Table 3 ). Date and density are supported and the weights are close to those of the optimal model. The date and density are the greatest explanatory variables with parameter likelihood values $>0.4$ (Table 4). 
Table 1 Sampling food density and focal observations over three winter stages of Hooded Cranes

\begin{tabular}{llcllcc}
\hline Period & Habitat & Food density $\left(\mathbf{g} / \mathbf{m}^{\mathbf{2}}\right)$ & $\begin{array}{l}\text { Rate of foraging } \\
\text { success (times/s) }\end{array}$ & Sample size & Foraging effort & Sample size \\
\hline Early stage & Paddy fields & $123.395 \pm 25.699$ & $0.105 \pm 0.051$ & 25 & $0.682 \pm 0.294$ & 51 \\
& Meadows & $212.200 \pm 141.144$ & $0.063 \pm 0.036$ & 43 & $0.698 \pm 0.291$ & 50 \\
& Mudflats & $14.023 \pm 5.897$ & $0.048 \pm 0.048$ & 47 & $0.656 \pm 0.151$ & 37 \\
Middle stage & Paddy fields & $93.206 \pm 28.547$ & $0.099 \pm 0.057$ & 29 & $0.752 \pm 0.202$ & 58 \\
& Meadows & $248.330 \pm 121.451$ & $0.050 \pm 0.046$ & 62 & $0.781 \pm 0.165$ & 66 \\
\multirow{2}{*}{ Late stage } & Mudflats & $14.498 \pm 10.908$ & $0.031 \pm 0.024$ & 60 & $0.671 \pm 0.257$ & 55 \\
& Paddy fields & $62.563 \pm 25.253$ & $0.058 \pm 0.027$ & 55 & 0.185 & 8 \\
& Meadows & $198.595 \pm 117.354$ & $0.070 \pm 0.038$ & 30 & 0.156 & 41 \\
\hline
\end{tabular}

Table 2 Regression equations describing changes in food resource density of six sample plots in the winter

\begin{tabular}{lll}
\hline Habitat & Sample plot & Regression equation \\
\hline Mudflats & A & Food density $=13.816-0.21 *$ date \\
& B & Food density $=17.210-0.114^{*}$ date \\
Meadows & C & Food density $=209.691+0.543 *$ date \\
& D & Food density $=167.587+1.386 *$ date \\
Paddy fields & E & Food density $=119.191-0.787 *$ date \\
& F & Food density $=143.896-2.151 *$ date \\
\hline
\end{tabular}

Date is scaled so that 1 November $2014=1$

Table 3 General mixed linear models evaluating variation in foraging effort of wintering Hooded Cranes

\begin{tabular}{lrrc}
\hline Model & $\boldsymbol{k}$ & $\boldsymbol{\Delta A I C}$ & $\boldsymbol{w}_{\boldsymbol{i}}$ \\
\hline Date & 5 & 0.0000 & 0.310 \\
Density + date & 6 & 0.0257 & 0.306 \\
Individual + environmental + density + date & 11 & 0.4847 & 0.243 \\
Individual + density + date & 8 & 1.5651 & 0.142 \\
Null & 2 & 18.4551 & 0.000 \\
\hline
\end{tabular}

Models that contained date and density as explanatory variables were well supported (Table 4). Date had the largest parameter-likelihood value of 0.99 and density also had a large parameter-likelihood value, i.e., 0.68 (Table 4). The variable referred to as Individual (i.e., age and family size effects) was not well supported, and minutes for searching and handling varied relatively little in relation to individual (parameter likelihood $=0.37$ ). Similarly, environmental variables received less support (parameter likelihood $=0.23$ ), while environmental factors had the least effect on foraging effort.
Table 4 Parameter likelihood and weighted-parameter estimates \pm standard error (SE) from general linear mixed models

\begin{tabular}{lll}
\hline $\begin{array}{l}\text { Explanatory } \\
\text { variable }\end{array}$ & $\begin{array}{l}\text { Parameter } \\
\text { likelihood }\end{array}$ & $\begin{array}{l}\text { Parameter } \\
\text { estimate } \pm \text { SE }\end{array}$ \\
\hline $\begin{array}{ll}\text { Intercept } \\
\text { Density }\end{array}$ & $\begin{array}{l}56.753 \pm 1.627 \\
\text { Environmental }\end{array}$ & $0.68 .656 \pm 27.724$ \\
Habitat & 0.23 & $-0.087 \pm 0.149$ \\
Time of day & & $-0.016 \pm 0.058$ \\
Winter duration & & $23.529 \pm 7.857$ \\
Individual & 0.37 & \\
Age & & $-0.011 \pm 0.026$ \\
Size & & $-0.021 \pm 0.018$ \\
Date & 0.99 & \\
Date & & $3.713 \pm 27.891$ \\
Date & &
\end{tabular}

Variation in foraging behavior in response to changes in food density and disturbance

The results of the generalized linear model showed that food density and disturbances had different effects on the rate of foraging success during the winter periods, while the effect of foraging effort was not significant. The rate of foraging success was markedly affected by food density during the middle and late winter (Table 5). Moreover, the disturbances and the combined action of food density and disturbances had a significant effect on the rate of foraging success in the late winter (Table 5). Furthermore, the rate of foraging success was markedly affected by disturbances in the paddy fields. The combined action of food density and disturbances had a significant effect on the rate of foraging success in the meadows, while the effect of foraging effort was not significant in any of the three habitats (Table 6). 
Table 5 Effect of food density and disturbances on the foraging behavior of the Hooded Crane during three winter stages

\begin{tabular}{|c|c|c|c|c|c|}
\hline \multirow[t]{2}{*}{ Period } & \multirow[t]{2}{*}{ Factors } & \multicolumn{2}{|c|}{$\begin{array}{l}\text { Rate of foraging } \\
\text { success }\end{array}$} & \multicolumn{2}{|c|}{$\begin{array}{l}\text { Foraging } \\
\text { effort }\end{array}$} \\
\hline & & $F$ & $p$ & $F$ & $p$ \\
\hline \multirow[t]{3}{*}{ Early stage } & Food density & 0.520 & 0.989 & 0.762 & 0.832 \\
\hline & Disturbance & 0.293 & 0.746 & 0.266 & 0.767 \\
\hline & Density $\times$ disturbance & 0.319 & 1.000 & 0.823 & 0.780 \\
\hline \multirow[t]{3}{*}{ Middle stage } & Food density & 2.013 & $0.010^{* *}$ & 1.093 & 0.394 \\
\hline & Disturbance & 1.846 & 0.161 & 0.898 & 0.409 \\
\hline & Density $\times$ disturbance & 0.208 & 1.000 & 0.943 & 0.604 \\
\hline \multirow[t]{3}{*}{ Late stage } & Food density & 25.677 & $0.003^{* *}$ & 1.172 & 0.502 \\
\hline & Disturbance & 3.152 & $0.050^{*}$ & 0.027 & 0.974 \\
\hline & Density $\times$ disturbance & 7.907 & $0.000^{* * *}$ & 0.575 & 0.928 \\
\hline \multirow{3}{*}{ All stages } & Food density & 0.976 & 0.588 & 1.032 & 0.431 \\
\hline & Disturbance & 0.442 & 0.643 & 0.179 & 0.836 \\
\hline & Density $\times$ disturbance & 0.419 & 1.000 & 0.933 & 0.674 \\
\hline
\end{tabular}

Samples: $n=341$ at all stages, $n=125$ at the early stage, $n=157$ at the middle stage, $n=59$ at the late stage

* $0.01<p<0.05$; ${ }^{* *} 0.001<p<0.01$; *** $p<0.001$

Table 6 Effect of food density and disturbances on the foraging behavior of the Hooded Crane in different habitats

\begin{tabular}{|c|c|c|c|c|c|}
\hline \multirow[t]{2}{*}{ Habitats } & \multirow[t]{2}{*}{ Factors } & \multicolumn{2}{|c|}{$\begin{array}{l}\text { Rate of foraging } \\
\text { success }\end{array}$} & \multicolumn{2}{|c|}{$\begin{array}{l}\text { Foraging } \\
\text { effort }\end{array}$} \\
\hline & & $F$ & $p$ & $F$ & $p$ \\
\hline \multirow[t]{3}{*}{ Paddy fields } & Food density & 1.089 & 0.441 & 0.584 & 0.948 \\
\hline & Disturbance & 8.330 & $0.000^{* * *}$ & 0.114 & 0.892 \\
\hline & Density $\times$ disturbance & 0.207 & 1.000 & 1.085 & 0.423 \\
\hline \multirow[t]{3}{*}{ Meadows } & Food density & 0.908 & 0.647 & 1.065 & 0.450 \\
\hline & Disturbance & 2.656 & 0.074 & 1.203 & 0.303 \\
\hline & Density $\times$ disturbance & 4.419 & $0.000^{* * *}$ & 0.432 & 1.000 \\
\hline \multirow[t]{3}{*}{ Mudflats } & Food density & 0.720 & 0.845 & 1.269 & 0.276 \\
\hline & Disturbance & 1.100 & 0.337 & 0.297 & 0.744 \\
\hline & Density $\times$ disturbance & 0.213 & 1.000 & 1.115 & 0.375 \\
\hline
\end{tabular}

Samples: $n=104$ in the paddy fields, $n=146$ in the meadows, $n=91$ in the mudflats

${ }^{*} 0.01<p<0.05$; ${ }^{* *} 0.001<p<0.01$; ${ }^{* * *} p<0.001$

\section{Discussion}

An understanding of the variation in foraging efforts by Hooded Cranes provides an indication of habitat quality (Lewis et al. 2008). At low food densities, the prediction was that cranes would increase their foraging effort, expressed as searching time, to compensate for the lower likelihood of encountering food; the opposite is true for high food densities. The cranes increased their foraging effort to compensate for decreased food availability at their traditional, but degraded, foraging sites. Human disturbance also increased the time the cranes spend processing food and decreased their intake rate, causing the cranes to expend more effort (Richman and Lovvorn 2003).

The variation in the rate of foraging success, caused by changes in food density, could be used to measure directly the acquisition of food on the part of the cranes. The rate of foraging success decreased in each habitat with abundant food but high disturbance to ensure more secure access to food. In addition, disturbances reduced the intake rate (Gyimesi et al. 2010). When food sources were lacking in their traditional foraging habitats, waterbirds are more likely to feed in higher risk areas, such as paddy fields (Inger et al. 2006; Godvik et al. 2009).

With wetland degradation and loss, the number of traditional food sources declined and foraging sites of these cranes shifted to meadows and paddy fields. On the whole, our results suggest that the variation in food density at Shengjin Lake was relatively negligible from the perspective of Hooded Cranes. In the event of food shortages, the cranes are expected to increase their foraging effort to compensate for the decreased probability of food encounters. When food is scarce, the availability of food and foraging costs may have a great impact on the choice of foraging sites (Nolet and Klaassen 2009).

At Shengjin Lake, the carrying capacity of birds feeding on tubers has decreased and the amount and quality of the food available also declined. Although Shengjin Lake is a degraded wetland, it provides an important habitat for Hooded Cranes in the winter, which is further proof of their dependence on wetlands. The number of Hooded Cranes declined in 2009/2010, suggesting a collapse in their natural winter food supply (Zhou et al. 2009). The lack of food in the lake was the cause of the shift in behavior at the three habitats. In light of these results, we recommend promoting Vallisneria restoration, reducing livestock grazing and human disturbance in the lake to increase the food availability remain within the threshold of foraging.

\section{Conclusions}

Changes in foraging behavior were significant in our three habitats, given that Hooded Cranes responded to the reduction in food availability and the collapse in their natural winter food supply. Food density and disturbances had different effects on the rate of foraging success during the winter periods in the three habitats, while the effect of foraging effort was not significant. Observed variations in food density were relatively minor from the perspective of the foraging cranes at Shengjin Lake. Cranes have flexible foraging strategies and make full use of foraging habitats to improve their fitness. 


\section{Authors' contributions}

WW and LZ conceived and designed the experiments. WW performed the experiments and WW and $L Z$ analyzed the data. $L Z$ contributed the reagents/ materials analysis tools. WW and LZ wrote the paper while LZ liaised with the authorities of the nature reserve and obtained provincial guidance for field work. SY participated in the field work. All authors read and approved the final manuscript.

\section{Author details}

1 School of Resources and Environmental Engineering, Anhui University, 111 Jiulong Road, Hefei 230601, China. ${ }^{2}$ Institute of Biodiversity and Wetland Ecology, Anhui University, 111 Jiulong Road, Hefei 230601, China. ${ }^{3}$ Anhui Biodiversity Information Center, 111 Jiulong Road, Hefei 230601, China. ${ }^{4}$ Shengjin Lake National Nature Reserve of Anhui Province, Chizhou 247200, China.

\section{Acknowledgements}

The work was supported by the National Natural Science Foundation of China (Grant No. 31472020, 31172117) and the Graduate Student Innovation Research Projects of Anhui University (YQH100287). We express appreciation to Dr. Jinming Zhao for his helpful comments and suggestions on our study and the staff of the Shengjin Lake National Nature Reserve for their helps in the field work.

\section{Competing interests}

The authors declare that they have no competing interests

Received: 20 March 2016 Accepted: 20 July 2016

Published online: 17 August 2016

\section{References}

Barzen JA, Engels M, Burnham J, Harris J, Wu GF. Potential impacts of a water control structure on the abundance and distribution of wintering waterbirds at Poyang Lake. J Jpn Statist Soc. 2009;38:293-309.

Beauchamp G. Group-size effects on vigilance: a search for mechanisms. Behav Process. 2003:63:111-21.

Cao L, Barter MA, Lei G. New population estimates for Anatidae spending the non-breeding season in eastern China: implications for flyway population estimates. Biol Conserv. 2008;141:2301-9.

Cheng YQ, Cao L, Barter M, Xu W, Zhang Y, Zhao M. Wintering waterbird Survey at the Anhui Shengjin Lake National Nature Reserve, China 2008/2009. Hefei: University of Science and Technology of China Press; 2009.

Fang J, Wang Z, Zhao S, Li Y, Tang Z, Yu D, Ni L, Liu H, Xie P, Da L, Li Z, Zheng C. Biodiversity changes in the lakes of the Central Yangtze. Front Ecol Environ. 2006;4:369-77.

Fischer JB, Griffin CR. Feeding behavior and food habits of wintering Harlequin Ducks at Shemya Island, Alaska. Wilson Bull. 2000;112:318-25.

Fox AD, Hearn RD, Cao L, Cong PH, Wang X, Zhang Y, Dou ST, Shao XF, Barter $M$, Rees E. Preliminary observations of diurnal feeding patterns of swan geese Anser cygnoides using two different habitats at Shengjin Lake, Anhui Province, China. Wildfowl. 2008;58:20-30.

Fox AD, Cao L, Zhang Y, Barter M, Zhao MJ, Meng FJ, et al. Declines in the tuber-feeding waterbird guild at Shengjin Lake National Nature Reserve, China - a barometer of submerged macrophyte collapse. Aquat Conser Mar Freshw Ecosyst. 2011;21:82-91.

Gillespie GE, Kronlund AR. A manual for intertidal clam surveys. Canadian technical report of fisheries and aquatic science 2270, Fisheris and Oceans Canada, Pacific Biological Station; 1999.

Godvik IMR, Loe LE, Vik JO, Vr V, Langvatn R, Mysterud A. Temporal scales, trade-offs, and functional responses in red deer habitat selection. Ecology. 2009;90:699-710.

Guillemette M. The effect of time and digestion constraints in Common Eiders while feeding and diving over blue mussel beds. Funct Ecol. 1998;12:123-31

Gyimesi A, Stillman RA, Nolet BA. Cryptic interference competition in swans foraging on cryptic prey. Anim Behav. 2010;80:791-7.
Hill DA, Ellis N. Survival and age related changes in the foraging behaviour and time budget of Tufted Ducklings Aythya fuligula. Ibis. 1984;126:544-50.

Inger R, Bearhop S, Robinson JA, Ruxton G. Prey choice affects the trade-off balance between predation and starvation in an avian herbivore. Anim Behav. 2006;71:1335-41.

Jiang HX, Xu WB, Qian FW, Chu GZ. Impact of habitat evolvement and human disturbance on wintering water birds in Shengjin Lake of Anhui Province, China. Chin J Appl Ecol. 2007;18(8):1832-6.

Krebs JR. Optimal foraging: Decision rules for predators. In: Krebs JR, Davies NB, editors. Behavioural ecology: an evolutionary approach. Oxford: Blackwell; 1978. p. 23-63.

Krebs JR, Stephens DW, Sutherland WJ. Perspectives in optimal foraging. In: Bush AH, Clark Jr CA, editors. Perspectives in ornithology: essays presented for the centennial of the American Ornithologists' Union. Cambridge: Cambridge University Press; 1983. p. 165-221.

Kuwae T, Miyoshi E, Sassa S, Watabe Y. Foraging mode shift in varying environmental conditions by dunlin Calidris alpina. Mar Ecol Prog Ser. 2010:406:281-9.

Lewis TL, Esler D, Boyd WS. Effects of predation by sea ducks on clam abundance in soft-bottom intertidal habitats. Mar Ecol Prog Ser. 2007;329:131-44

Lewis TL, Esler D, Boyd WS. Foraging behavior of surf scoters (Melanitta perspicillata) and white-winged scoters (M. Fusca) in relation to clam density: inferring food availability and habitat quality. Auk. 2008;125:149-57.

Li Z, Wang Z, Ge C. Time budgets of wintering Red-Crowned Cranes: effects of habitat, age and family size. Wetlands. 2013;33:227-32.

Li C, Zhou L, Xu L, Zhao N, Beauchamp G. Vigilance and activity time-budget adjustments of wintering hooded cranes, Grus monacha, in humandominated foraging habitats. PLoS ONE. 2015;10(3):e0118928.

Littell RC, Pendergast J, Natarajan R. Modeling covariance structure in the analysis of repeated measures data. Stat Med. 2000;19:1793-819.

Lovvorn JR. Distributional responses of Canvasback ducks to weather and habitat change. J Appl Ecol. 1989:26:113-30.

May R, Mclean A. Theoretical ecology. New York: Oxford University Press; 2010.

Meng RX. The aquatic vegetation of Shengjin Lake. J Anhui Univ (Nat Sci Sect). 1979;3:71-80 (in Chinese)

Nolet BA, Klaassen M. Retrodicting patch use by foraging swans in a heterogeneous environment using a set of functional responses. Oikos. 2009;118:431-43.

Pyke GH. Optimal foraging theory: a critical review. Annu Rev Ecol Syst. 1984;15:523-75.

Pyke GH, Pulliam HR, Charnov EL. Optimal foraging: a selective review of theory and tests. Quart Rev Biol. 1977;52:137-54.

Richman SE, Lovvorn JR. Effects of clam species dominance on nutrient and energy acquisition by Spectacled Eiders in the Bering Sea. Mar Ecol Prog Ser. 2003;261:283-97.

Stephens DW, Krebs JR. Foraging theory. New Jersey: Princeton University Press; 1986.

Systad GH, Bustnes JO, Erikstad KE. Behavioral responses to decreasing day length in wintering sea ducks. Auk. 2000;117:33-40.

Tome MW. Optimal foraging: food patch depletion by Ruddy Ducks. Oecologia. 1988;76:27-36.

Yang L, Zhou L, Song Y. The effects of food abundance and disturbance on foraging flock patterns of the wintering Hooded Crane (Grus monacha). Avian Res. 2015:6:1-8.

Yasué M. Environmental factors and spatial scale influence shorebirds' responses to human disturbance. Biol Conserv. 2006;128:47-54.

Zhang JX, Lu JJ. Feeding ecology of two wintering geese species at Poyang Lake, China. J Freshw Ecol. 1999;14:439-45.

Zheng M, Zhou L, Zhao N, Xu W. Effects of variation in food resources on foraging habitat use by wintering Hooded cranes (Grus monacha). Avian Res. 2015;6:1-10.

Zhou B, Zhou L, Chen J, Xu W, Cheng Y. Assemblage dynamics and territorial behaviour of hooded crane in winter at Shengjin Lake. Chin J Wildl. 2009;30:133-6 (in Chinese) 